\title{
Engineering Escherichia coli for succinate production from hemicellulose via consolidated bioprocessing
}

\author{
Zongbao Zheng ${ }^{1,2}$, Tao Chen ${ }^{1,2^{*}}$, Meina Zhao ${ }^{1,2}$, Zhiwen Wang ${ }^{1,2}$ and Xueming Zhao ${ }^{1,2}$
}

\begin{abstract}
Background: The recalcitrant nature of hemicellulosic materials and the high cost in depolymerization are the primary obstacles preventing the use of xylan as feedstock for fuel and chemical production. Consolidated bioprocessing, incorporating enzyme-generating, biomass-degrading and bioproduct-producing capabilities into a single microorganism, could potentially avoid the cost of the dedicated enzyme generation in the process of xylan utilization. In this study, we engineered Escherichia coli strains capable of exporting three hemicellulases to the broth for the succinate production directly from beechwood xylan.

Results: Xylanases were extracellular environment-directed by fusing with OsmY. Subsequently, twelve variant OsmY fused endoxylanase-xylosidase combinations were characterized and tested. The combination of XynC-A from Fibrobacter succinogenes 585 and XyloA from Fusarium graminearum which appeared to have optimal enzymatic properties was identified as the best choice for xylan hydrolysis $(0.18 \pm 0.01 \mathrm{~g} / \mathrm{l}$ protein in the broth with endoxylanase activity of $12.14 \pm 0.34 \mathrm{U} / \mathrm{mg}$ protein and xylosidase activity of $92 \pm 3 \mathrm{mU} / \mathrm{mg}$ protein at $8 \mathrm{~h}$ after induction). Further improvements of hemicellulases secretion were investigated by Ipp deletion, $d s b A$ overexpression and expression level optimization. With co-expression of $\alpha$-arabinofuranosidase, the engineered $E$. coli could hydrolyze beechwood xylan to pentose monosaccharides. The hemicellulolytic capacity was further integrated with a succinate-producing strain to demonstrate the production of succinate directly from xylan without externally supplied hydrolases and any other organic nutrient. The resulting E. coli Z6373 was able to produce $0.37 \mathrm{~g} / \mathrm{g}$ succinate from xylan anaerobically equivalent to $76 \%$ of that from xylan acid hydrolysates.

Conclusions: This report represents a promising step towards the goal of hemicellulosic chemical production. This engineered $E$. coli expressing and secreting three hemicellulases demonstrated a considerable succinate production on the released monosaccharides from xylan. The ability to use lower-cost crude feedstock will make biological succinate production more economically attractive.
\end{abstract}

Keywords: Consolidated bioprocessing, Escherichia coli, Hemicellulose, Succinate, Xylan

\section{Background}

Lignocellulosic biomass represents an abundant, lowcost and renewable source of fermentable sugars. It is an alternative candidate besides petroleum as feedstock for fuel and chemical production [1]. Generally, lignocellulosic biomass comprises of $35-50 \%$ cellulose, 20 $35 \%$ hemicellulose and $10-25 \%$ lignin [2]. As the major

\footnotetext{
* Correspondence: chentao@tju.edu.cn

'Key Laboratory of Systems Bioengineering, Ministry of Education, Tianjin University, Tianjin 300072, People's Republic of China

Full list of author information is available at the end of the article
}

component of hemicellulose, xylan is one of the most abundant natural polysaccharides with a $\beta-(1,4)$-linked xylose homopolymeric backbone. The side groups can be substituted with arabinose, glucose, galactose or glucuronic acid, based on the sources of xylan [3]. Recent research on utilizing xylan as feedstock boost development of numerous-promising processes for a variety of fuels and chemicals, such as biodiesel [4], xylitol [5], biohydrogen [6] and ethanol [7,8]. However, high cost in depolymerization is a primary obstacle preventing the use of xylan as feedstock $[9,10]$.

\section{Biomed Central}


Currently, the conversion of xylan by microorganisms requires a two-step process: acid or enzymatic hydrolysis of xylan into monosaccharides followed by the bioconversion of pentoses into bioproducts [7]. Complete acid hydrolysis generates fermentation inhibitors like furfural and hydroxymethylfurfural that complicate biological utilization [11]. On the other hand, enzymatic hydrolysis usually employs xylanase preparations produced by organisms which featuring dedicated xylanase production with high cost and low efficiency [7]. An alternative approach, known as consolidated bioprocessing (CBP), could potentially avoid the cost of the dedicated enzyme generation step by incorporating enzyme-generating, biomass-degrading and bioproduct-producing capabilities into a single organism through genetic engineering [12].

E. coli has been characterized as a good xylose utilizer. However, it cannot directly hydrolyze xylan. The pathway of xylan hydrolysis should be incorporated to add saccharifying traits to the microorganism. Besides, nonpathogenic laboratory strains of $E$. coli generally excrete only trace amounts of proteins into the culture medium under normal growth conditions [13]. So additional engineering is necessary to enhance the protein secretion of the microorganism. Osmotically inducible protein $\mathrm{Y}$ (OsmY), one of the most efficient excreting fusion partners in E. coli, has been used as a carrier protein to excrete various recombinant proteins of different origin and sizes into the medium at high levels [14]. The conversion of xylan to biodiesel by $E$. coli has been successfully obtained in an aerobic fermentation with two OsmY and xylanases fusion proteins [4]. However, due to relatively low enzyme activity and the fermentation process selected, the hydrolysis and conversion efficiency was fairly low, and the fatty acid ethyl esters yield from xylan was less than a quarter of that from glucose.

In the process of xylan conversion, metabolic engineering and synthetic biology are emerging as powerful approaches to realize the biorefinery construction [15]. New cellular systems created could convert lignocellulose to a wide range of metabolites. One of these metabolites, succinate, has been identified as one of the top 12 building blocks from lignocellulosic biomass [16]. Succinate is widely used as diesel fuel additives, deicers, solvents, and detergent builders. Besides, its potential value, as a 4-carbon building block for a number of higher value polymers, also arouse great interests [17]. Currently, the majority of succinate is manufactured petrochemically from butane via maleic anhydride. To reduce the cost of the process, alternative low-cost renewable routes from biomass carbohydrates by microbial fermentation have been highly sought after [18]. E. coli strains which can efficiently ferment a variety of sugars presented as polymeric constituents of lignocellulose to succinate have been developed [19]. Fermentations of lignocellulosic hydrolysates to succinate by $E$. coli have been carried out using acid hydrolysates of rice straw [20], softwood [21] and enzymatic hydrolysates of corn stalk [22]. It is notable that these studies adopted separate hydrolysis and fermentation (SHF) that the process of lignocellulose hydrolysis was discrete with the process of succinate production. To our knowledge, succinate production process performed by $E$. coli from lignocellulose in the form of simultaneous saccharification and fermentation (SSF [9]) has not been demonstrated before, not to mention the CBP.

Herein a successful CBP of xylan to succinate performed by $E$. coli is described. The potential of hemicellulases production and secretion from $E$. coli were explored. Beechwood xylan was hydrolyzed by the engineering $E$. coli, and the monosaccharides produced were simultaneously converted to succinate with the same strain. It is believed that this is the first CBP designed for the conversion of xylan to succinate by metabolically engineered $E$. coli strains.

\section{Results and discussion}

\section{Target gene selection}

Endoxylanase and xylosidase were firstly chosen for xylan hydrolysis guided by the following considerations. Endoxylanase randomly cleaves the $\beta-1,4$ bonds in the xylan backbone to yield oligosaccharides, xylobiose and xylose [23]. The resulting xylooligosaccharides are further attacked by xylosidase at the non-reducing end, generating xylose [2]. A significant synergy exists between the two enzymes in the process of xylan hydrolysis.

To explore suitable xylanases to be expressed and exported from E. coli for xylan hydrolysis, a list of hundreds of candidate enzymes on the basis of known activities with xylan or xylobiose as substrate was developed. These xylanases were prioritized according to the enzyme activity between $30-37^{\circ} \mathrm{C}$ which was the optimal temperature for $E$. coli growth and fermentation. As most xylanases exhibited maximum activities at high temperatures, the enzyme activities are relatively low between $30-37^{\circ} \mathrm{C}$. Among them, seven candidate enzymes [24-29] with higher enzyme activities between $30-37^{\circ} \mathrm{C}$ were selected for the following operon construction and in vitro testing to screen the optimal hydrolase combinations in CBP, including three types of endoxylanases and four types of xylosidases which are listed in Table 1.

\section{In vitro xylanase characterization}

To hydrolyze xylan with high efficiency, a great amount of endoxylanases and xylosidases must be simultaneously produced and exported into the broth by $E$. coli 
Table 1 Designations and sources of candidate xylanases

\begin{tabular}{|c|c|c|c|c|c|c|}
\hline Xylanase No. & Gene name & Preferred substrate & Protein Size (kDa) & Source organism & $\begin{array}{l}\text { GenBank } \\
\text { ID }\end{array}$ & Reference \\
\hline E1 & $x y / D$ & xylan & 45 & Fusarium graminearum & NT_086561 & [24] \\
\hline E2 & xyn10B & xylan & 44.3 & Clostridium stercorarium & $2106153 \mathrm{~A}$ & [25] \\
\hline E3 & $x y n C-A$ & xylan & 28.2 & Fibrobacter succinogenes S85 & U01037 & [26] \\
\hline $\mathrm{X} 4$ & $x s a$ & xylobiose & 38 & Bacteroides ovatus & AAB08024 & [27] \\
\hline $\mathrm{X} 5$ & $x y n B$ & xylobiose & 56 & Bacillus pumilus IPO & CAA29235 & [28] \\
\hline $\mathrm{X6}$ & $x s a$ & xylobiose & 61 & Selenomonas ruminantium GA192 & AAB97967 & [29] \\
\hline $\mathrm{X7}$ & $x y / O A$ & xylobiose & 42 & Fusarium graminearum & AAT84260 & [24] \\
\hline
\end{tabular}

strains. In order to obtain the highest hydrolysis efficiency, twelve $\mathrm{pA}-\mathrm{E}_{\mathrm{m}} \mathrm{X}_{\mathrm{n}}$ series plasmids were transformed into $E$. coli BL21 (DE3), and all the 12 engineered strains expressing different endoxylanasexylosidase combinations were tested to screen the optimal xylanases combination.

The enzyme activities of each xylanase combination in vitro are shown in Table 2 . For all the 12 strains, the enodxylanase and xylosidase were co-expressed and secreted well, resulting in both endoxylanase and xylosidase activities in culture broth distinctly, whereas the host strain transformed with empty plasmid backbone did not exhibit any xylanase activity. The 12 xylanase expression plasmids were derived from the same parent plasmid, pTrc99z, with same copy number, same promoter driving xylanases expression, and same secretion mechanism adopted. However, the secretions of the proteins varied widely. This may be attributed to the different structures of the xylanases which would alter the efficiency of protein transportation and affect the secretion of other proteins. Among them, Z1170 secreted $0.95 \pm 0.03 \mathrm{~g} / \mathrm{l}$ protein at $24 \mathrm{~h}$ after induction with low cell density in shake-flask cultivation, showing great potential of osm $Y$ fusion strategy for extracellular recombinant protein production.

Among the seven strains with the maximum $\mathrm{OD}_{600}$ exceeding 4.5 tested in this study, Z1370 (coding endoxylanase XynC-A from Fibrobacter succinogenes S85 and xylosidase XyloA from Fusarium graminearum) exhibited the optimal enzymatic properties. Z1370 secreted $0.18 \pm 0.01 \mathrm{~g} / \mathrm{l}$ protein and exhibited a highest xylosidase activity of $92 \pm 3 \mathrm{mU} / \mathrm{mg}$ protein, a relatively high endoxylanase activity of $12.14 \pm 0.34 \mathrm{U} / \mathrm{mg}$ protein at 8 $\mathrm{h}$ after induction. It has been reported that xylosidase is the rate-limiting enzyme compared to endoxylanase in xylan hydrolysis [30], which is consistent with the results shown in Table 2 . Considering the high xylanase activities especially xylosidase activity, the quantity of protein secretion as well as the effect of protein expression on cell growth of $E$. coli, the artifical operon $\mathrm{P}_{\text {trc }}{ }^{-}$

Table 2 The physiology and enzymatic properties of Z1EXO series strains

\begin{tabular}{|c|c|c|c|c|c|c|c|c|}
\hline \multirow[t]{2}{*}{ Strain } & \multirow[t]{2}{*}{ Xylanases expressed } & \multirow[t]{2}{*}{ Max $\mathrm{OD}_{600}$} & \multicolumn{2}{|c|}{ Protein secretion $(\mathrm{g} / \mathrm{l})$} & \multicolumn{2}{|c|}{ Endoxylanase activity } & \multicolumn{2}{|c|}{ Xylosidase activity } \\
\hline & & & $8 h(16 h)^{a}$ & $24 \mathrm{~h}$ & $(U / L)$ & (U/mg) & $(U / L)$ & $(\mathrm{mU} / \mathrm{mg})$ \\
\hline Bl21(DE3) & - & $6.50 \pm 0.17$ & $0.03 \pm 0$ & $0.03 \pm 0$ & n.d. ${ }^{b}$ & n.d. ${ }^{b}$ & n.d. ${ }^{\mathrm{b}}$ & n.d. ${ }^{\mathrm{b}}$ \\
\hline Z1000 & - & $6.19 \pm 0.08$ & $0.04 \pm 0$ & $0.03 \pm 0$ & n.d. ${ }^{b}$ & n.d. ${ }^{b}$ & n.d. ${ }^{b}$ & n.d. ${ }^{b}$ \\
\hline Z1140 & $E_{1}, X_{4}$ & $3.45 \pm 0.04$ & $0.30 \pm 0.02$ & $0.69 \pm 0$ & $398 \pm 13$ & $1.31 \pm 0.07$ & $24 \pm 1.0$ & $80 \pm 4$ \\
\hline Z1150 & $E_{1}, X_{5}$ & $4.08 \pm 0.12$ & $0.19 \pm 0.01$ & $0.31 \pm 0.03$ & $65 \pm 2$ & $0.34 \pm 0.01$ & $14.3 \pm 0.6$ & $75 \pm 4$ \\
\hline Z1160 & $E_{1}, X_{6}$ & $4.55 \pm 0.05$ & $0.10 \pm 0.01$ & $0.21 \pm 0.02$ & $75 \pm 0$ & $0.75 \pm 0.04$ & $6.1 \pm 0.3$ & $61 \pm 5$ \\
\hline Z1170 & $E_{1}, X_{7}$ & $2.02 \pm 0.05$ & $0.60 \pm 0.04$ & $0.95 \pm 0.03$ & $420 \pm 19$ & $0.70 \pm 0.04$ & $46.3 \pm 0.5$ & $77 \pm 3$ \\
\hline Z1240 & $E_{2}, X_{4}$ & $5.12 \pm 0.12$ & $0.10 \pm 0.01$ & $0.17 \pm 0.01$ & $274 \pm 10$ & $2.71 \pm 0.19$ & $8.0 \pm 0.3$ & $77 \pm 6$ \\
\hline $\mathrm{Z} 1250$ & $E_{2}, X_{5}$ & $5.69 \pm 0.29$ & $0.11 \pm 0.02$ & $0.12 \pm 0.03$ & $50 \pm 4$ & $0.47 \pm 0.03$ & $6.8 \pm 0.2$ & $63 \pm 7$ \\
\hline Z1260 & $E_{2}, X_{6}$ & $4.83 \pm 0.05$ & $0.07 \pm 0$ & $0.10 \pm 0$ & $90 \pm 5$ & $1.36 \pm 0.04$ & $4.5 \pm 0.2$ & $64 \pm 1$ \\
\hline Z1270 & $E_{2}, X_{7}$ & $4.07 \pm 0.05$ & $0.34 \pm 0.01$ & $0.43 \pm 0.02$ & $423 \pm 14$ & $1.25 \pm 0.04$ & $29.3 \pm 1.2$ & $86 \pm 3$ \\
\hline Z1340 & $E_{3}, X_{4}$ & $5.10 \pm 0.03$ & $0.08 \pm 0.01$ & $0.21 \pm 0.01$ & $1098 \pm 28$ & $13.22 \pm 1.05$ & $7.3 \pm 0.2$ & $88 \pm 7$ \\
\hline Z1350 & $E_{3}, X_{5}$ & $3.97 \pm 0.09$ & $0.22 \pm 0$ & $0.51 \pm 0.04$ & $1512 \pm 2$ & $6.88 \pm 0$ & $10.9 \pm 0.5$ & $49 \pm 1$ \\
\hline Z1360 & $E_{3}, X_{6}$ & $4.93 \pm 0.10$ & $0.08 \pm 0$ & $0.25 \pm 0$ & $996 \pm 1$ & $13.14 \pm 0.01$ & $5.9 \pm 0.2$ & $77 \pm 1$ \\
\hline Z1370 & $E_{3}, X_{7}$ & $5.04 \pm 0.05$ & $0.18 \pm 0.01$ & $0.25 \pm 0.01$ & $2151 \pm 14$ & $12.14 \pm 0.34$ & $16.3 \pm 0.2$ & $92 \pm 3$ \\
\hline
\end{tabular}

${ }^{a}$ Except maximum $\mathrm{OD}_{600}$, the sampling time was at the late-exponential phase, which was at about $8 \mathrm{~h}$ after induction for strains $\mathrm{Z} 13 \mathrm{X} 0$ and the two controls, and $16 \mathrm{~h}$ for the other strains.

b n.d.: not detectable. 
$\mathrm{E}_{3} \mathrm{X}_{7}$ was chosen as the xylan hydrolases gene cassette in all the following host-development work.

\section{Effects of Ipp deletion and $d s b A$ overexpression on the secretion and activities of xylanases}

In their previous works, Shin et al. (2007) demonstrated that with lpp gene (coding Braun's lipoprotein) deletion, the outer membrane permeability of $E$. coli was increased [31]. Periplasm-directed recombinant proteins could be secreted into the extracellular environment with high efficiency without significantly affecting cell growth [32]. To further enhance the secretion of the OsmY-fused xylanases which were extracellular environment-directed, lpp deletion of the engineering strains was explored.

The influences of $l p p$ deletion on the secretion and activities of the xylanases are shown in Table 3. The lpp deletion strain Z1371 exhibited a higher ability to excrete proteins, resulting higher xylanases activities. However, the specific enzyme activity was lower than that of control strain Z1370 without lpp deletion. The cell growth was also significantly affected as the maximum $\mathrm{OD}_{600}$ was only $40 \%$ of $\mathrm{Z} 1370$, which is not consistent with Shin's report [32]. We have doubted that the probable reason for this distinction was the different media used for strain culture. In this work the medium was M9/1\% glucose minimal medium, while Shin et al. (2007) used LB or M9/1.0\% casamino acid medium instead. However when Z1371 was cultured in LB medium, this detrimental effect was not ameliorated (data not shown). The periplasmic leaky phenotype caused by lpp deletion is not specific. Besides xylanases, other periplasmic proteins could also escape from cells, which maybe the true reason of cell growth retardation and the specific enzyme activity reduction. On the other hand, if a co-culture which could distribute the metabolic burden by dividing the microorganisms into hydrolyzer and producer was conducted, the strain with lpp deletion would be a good candidate for polymers hydrolysis. In the co-culture system, the growth rate of hydrolyzer (strains with lpp deletion) was slower than the producer. As a result, most of the hydrolyzed sugars would be utilized by the producer. However, as to the single strain fermentation conducted CBP, E. coli with lpp deletion is not a good choice.
To facilitate disulfide bond formation in the periplasm, the $d s b A$ gene encoding the disulfide oxidoreductase, E3 and X7 genes were co-expressed in strain Z2370. Xylanases excretion and the specific enzyme activities were slightly higher when the periplasmic oxidoreductase was co-expressed in E. coli as shown in Table 3. The increased excretion was probably due to the fact that DsbA co-expression increased the soluble protein level in the periplasm $[14,33]$, which further improved the specific enzyme activities of xylanases.

\section{Optimization of the expression level of xylanases}

In the course of transferring heterologous enzymatic pathways, it is easily induced a stress response from excessive heterologous protein by gene overexpression [34]. As shown in Figure 1, abundant xylanases were detected intracellular, which means that the capability of protein secretion was insufficient compared to that of protein expression. As aforementioned, two methods to assist xylanases export were investigated. However, even combination of expressing OsmY-fusion proteins in the $l p p$ deletion strain, not all of the xylanases were taken out of the cytoplasm. It seems likely that this bottleneck is hardly to be removed. In order to coordinate the fluxes and avoid unnecessary waste, the upstream flux of the rate-limiting step should be reduced, which refers to protein production. In the shake-flask culture with M9/1\% glucose medium, the maximum $\mathrm{OD}_{600}$ of BL21 (DE3) was $6.5 \pm 0.17$, and that of BL21 (DE3) harbouring $\mathrm{p}$ Trc $99 \mathrm{z}$ plasmid was $6.19 \pm 0.08$. On the contrary, the maximum $\mathrm{OD}_{600}$ of $\mathrm{Z} 1370$ was only $5.04 \pm 0.05$, the maximum specific growth rate was also lower (data not shown). The main reason of the differences among these strains was the metabolic burden caused by plasmid-born and protein expression.

Plasmid copy number is an important factor in genetic engineering as it affects the protein expression level of the cloned gene by gene dosage effect and exerts a metabolic burden on the cell. The plasmids used in the above work were all pTrc99a-derivatived, that is, the origin of replication is pBR322 with copy number of 36-41 [35]. In order to alleviate the metabolic burden caused by plasmid conservation and protein hyperexpression, a new set of three strains including Z3370, Z3371 and Z4370 were engineered. The replication origins of the harboured

Table 3 The physiology and enzymatic properties of the engineering strains with Ipp deletion or dsbA overexpression

\begin{tabular}{|c|c|c|c|c|c|c|c|}
\hline \multirow[t]{2}{*}{ Strain } & \multirow[t]{2}{*}{ Max. $O D_{600}$} & \multicolumn{2}{|l|}{ Protein $(g / l)$} & \multicolumn{2}{|c|}{ Endoxylanase activity } & \multicolumn{2}{|c|}{ Xylosidase activity } \\
\hline & & Intracellular & Extracellular & $(\mathrm{U} / \mathrm{L})$ & $(\mathrm{U} / \mathrm{mg})$ & $(\mathrm{U} / \mathrm{L})$ & $(\mathrm{mU} / \mathrm{mg})$ \\
\hline Z1370 & $5.04 \pm 0.05$ & $2.16 \pm 0.11$ & $0.18 \pm 0.01$ & $2151 \pm 14$ & $12.14 \pm 0.34$ & $16.3 \pm 0.2$ & $92 \pm 3$ \\
\hline Z1371 & $2.09 \pm 0.12$ & $1.24 \pm 0.07$ & $0.41 \pm 0.01$ & $2919 \pm 72$ & $7.16 \pm 0.17$ & $31.8 \pm 0.7$ & $78 \pm 2$ \\
\hline Z2370 & $4.43 \pm 0.06$ & $1.77 \pm 0.04$ & $0.21 \pm 0.01$ & $3024 \pm 97$ & $14.44 \pm 0.62$ & $20.7 \pm 0.1$ & $99 \pm 3$ \\
\hline
\end{tabular}




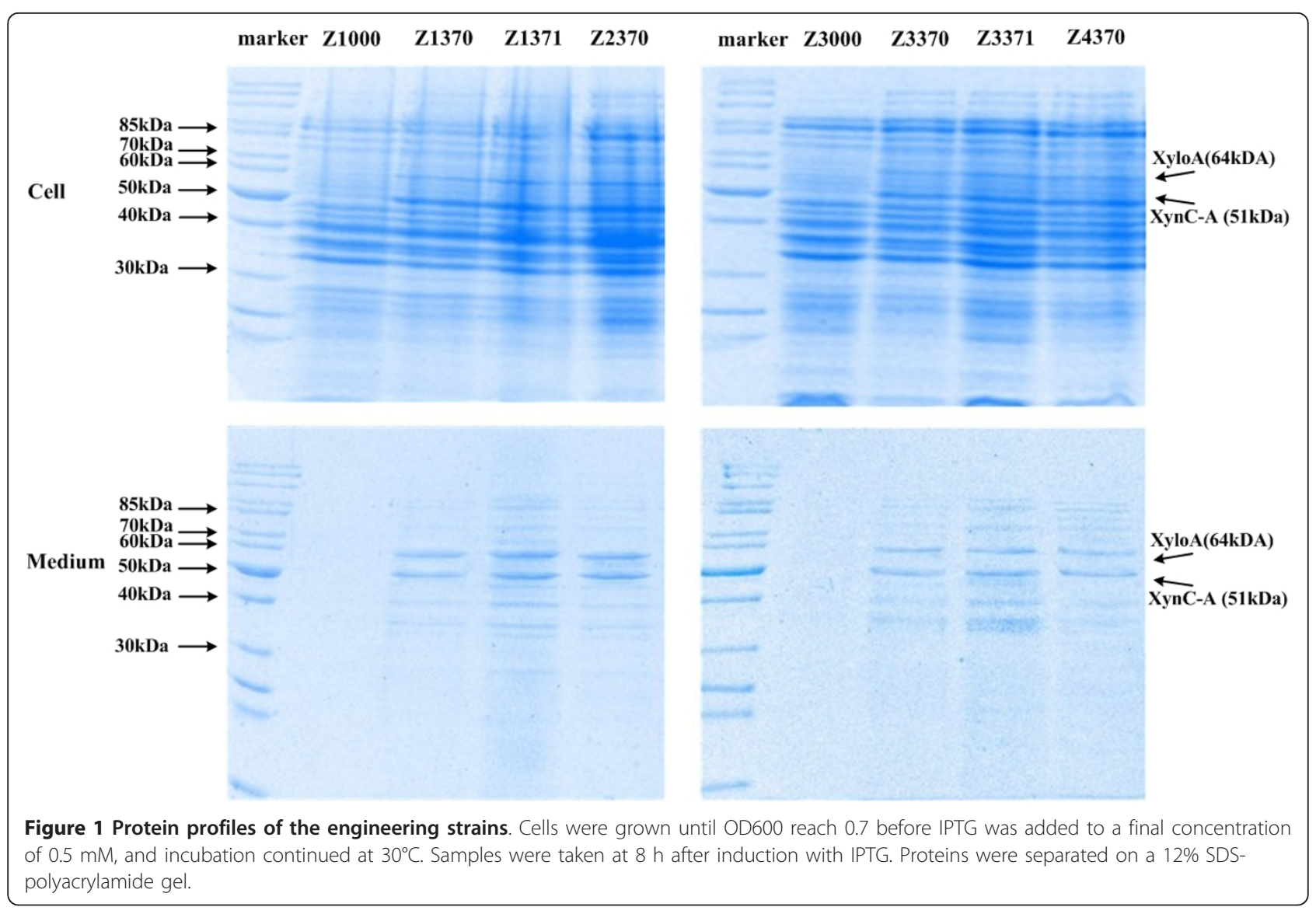

plasmids were changed to $\mathrm{p} 15 \mathrm{~A}$, the copy number of which were reduced to a relatively low number of 10-12 [36]. As seen from Table 4 the protein secretion of the new set of three strains were slightly lower than that of the corresponding strains harbouring pTrc99a-derivative plasmid, however, the maximum $\mathrm{OD}_{600}$ and specific growth rate were restored to a certain extent for these strains, especially for Z4370. This significant change can be attributed to the decrease of the cell's metabolic burden. The decrease of intracellular enzyme activities after changing the replication origins of the harboured plasmids also verified this conclusion to some extent from another side (data not shown). Though there were still a small amount of xylanases remained intracellular (Figure 1 ), the excess protein expression didn't severely hamper the cell growth anymore.
Strains expressed other enzyme combinations including Z1170 and Z1350 were also tested. When the expression of xylanases reduced, the performance of the two strains were not as good as predicted. For strain $\mathrm{Z} 1170$, the maximum $\mathrm{OD}_{600}$ was restored from 2.02 to 2.95 , however, the protein excretion was reduced to half. For strain Z1350, the maximum $\mathrm{OD}_{600}$ was unchanging, and the protein excretion was fell by a quarter.

\section{Effect of $a b f 2$ overexpression on the hydrolysis of xylan}

The biological activities of xylanases were further confirmed by using M9/0.2\% glucose $+1 \%$ xylan minimal medium for cell growth. However, the enzymatic hydrolysis of xylan was insufficient compared to acid hydrolysis (Figure 2). After acid hydrolysis, $8.6 \mathrm{~g}$ reducing sugar

Table 4 The physiology and enzymatic properties of the engineering strains harboring a p15A-devirative plasmid

\begin{tabular}{|c|c|c|c|c|c|c|c|}
\hline \multirow[t]{2}{*}{ Strain } & \multirow[t]{2}{*}{ Max. $O D_{600}$} & \multicolumn{2}{|l|}{ Protein (g/l) } & \multicolumn{2}{|c|}{ Endoxylanase activity } & \multicolumn{2}{|c|}{ Xylosidase activity } \\
\hline & & Intracellular & Extracellular & $(U / L)$ & (U/mg) & $(U / L)$ & $(\mathrm{mU} / \mathrm{mg})$ \\
\hline $\mathrm{Z3370}$ & $5.49 \pm 0.06$ & $0.53 \pm 0.03$ & $0.16 \pm 0.01$ & $1945 \pm 60$ & $12.48 \pm 0.57$ & $15.0 \pm 0.3$ & $94 \pm 4$ \\
\hline$Z 3371$ & $2.86 \pm 0.05$ & $0.13 \pm 0.02$ & $0.32 \pm 0.01$ & $2022 \pm 16$ & $6.32 \pm 0.12$ & $22.7 \pm 0.3$ & $71 \pm 2$ \\
\hline Z4370 & $5.75 \pm 0.10$ & $0.44 \pm 0.02$ & $0.18 \pm 0.01$ & $2581 \pm 97$ & $14.34 \pm 0.67$ & $17.0 \pm 0.2$ & $103 \pm 3$ \\
\hline
\end{tabular}




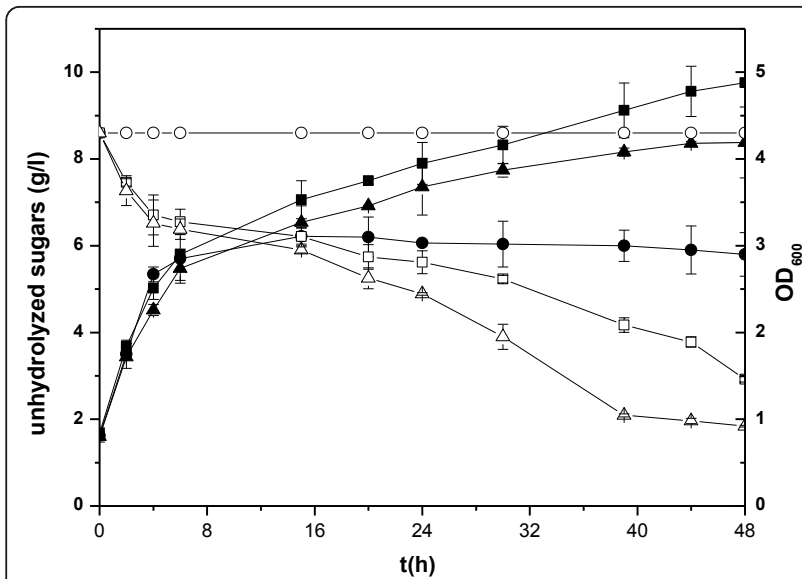

Figure 2 Cell density and unhydrolyzed sugars during cultivation of the engineered strains. Circle, Z3000; square, Z4370; triangle, Z5370; the solid symbols indicate $\mathrm{OD}_{600}$ and the hollow ones indicate unhydrolyzed sugars.

was obtained from $10 \mathrm{~g}$ xylan while only $5.68 \mathrm{~g}$ was liberated in the process of enzymatic digestion, which was equivalent to $66 \%$ of acid hydrolysis reducing sugar. The uncompleted enzymatic hydrolysis may due to the lack of accessory hemicellulases [2]. The substitutions on the side chains of xylan may hinder the formation of enzyme-substrate complexes, thus impede enzymatic hydrolysis [37]. Arabinose is the most frequent substitution of natural hemicellulose [2]. The $\alpha$-arabinofuranosidase catalyzes the hydrolysis of the non-reducing terminal $\alpha$-arabinofuranosidic side chains which would physically restrict access to the $\beta$ - $(1,4)$-xylosidic linkage in the xylan backbone and slow the action of endoxylanase and xylosidase. The combination of xylanase, xylosidase, and arabinofuranosidase can completely hydrolyze arabinoxylan in vitro [25]. Therefore, pB$\mathrm{E}_{3} \mathrm{X}_{7} \mathrm{AD}$ was constructed and transformed into BL21 (DE3) to obtain strain Z5370, in which abf2 (coding an $\alpha$-arabinofuranosidase originated from Bacillus subtilis 168 [38]), E3, X7 and $d s b A$ genes were co-expressed. The effect of $\alpha$-arabinofuranosidase on the improvement of hydrolysis efficiency of beechwood xylan is shown in Figure 2.

Forty-eight hours after induction, the degree of xylan hydrolysis was improved from $66 \%$ to $79 \%$ with $\alpha$-arabinofuranosidase co-expressed (Figure 2), indicating the importance of removing this substitution for generation of monomeric sugars. At the end of cultivation, there were still a small amounts of oligomers of the enzymatic hydrolysates not taken up by E. coli, 9\% for strain Z5370 while $15 \%$ for Z4370, which maybe substitutes of xylan that cannot be utilized by $E$. coli strains. It suggested that accessory hemicellulases should be existed in the broth to assist xylan hydrolysis. However, much more metabolic burden was exerted meantime, as shown in Figure 2. At $48 \mathrm{~h}$ after induction, the final $\mathrm{OD}_{600}$ of Z5370 was 4.2 while that of Z4370 was 4.9. A compromised strategy adopted should be concerned between the metabolic burden and the hydrolysis efficiency.

\section{CBP of xylan to succinate}

Achieving a functional xylan hydrolysis pathway in $E$. coli was the first step in engineering an organism for CBP of xylan to succinate. The second major step involved optimizing the host strain to channel hydrolyzed monosaccharides into succinate production pathway. A classic double-knockout strategy was operated, removing lactate dehydrogenase $(l d h A)$ and pyruvate formate lyase $(p f l B)$ genes to block the formation of byproducts (formate and lactate). In order to improve the xylose co-utilization efficiency with glucose, the glucose-specific permease of the phosphotransferase system (ptsG) gene was simultaneously knocked out to interfere with the regulation of catabolite repression [39]. In addition, pyc gene (coding a pyruvate carboxylase originated from Corynebacterium glutamicum ATCC 13032 [35]) was overexpressed to achieve higher yields of succinate by efficiently carboxylazing of pyruvate to oxaloacetate in this trimutant background.

Xylan hydrolysis pathway was introduced into the succinate-producing strain above mentioned to give strain Z6373. Z6373 could directly convert xylan to succinate under oxygen-deprived conditions. Fermentation of xylan was carried out through a two-stage process in which cells harvested from aerobic fermentation were suspended in AM1/1\% xylose (X) minimal medium supplemented 3\% xylan (BWX) for CBP. Fermentations with $1 \%$ and $4 \%$ pure xylose as carbon source were also conducted for comparison. A summary of the results from these studies is listed in Figure 3. As an aerobic cultivation for two-hour induction in AM1 medium was

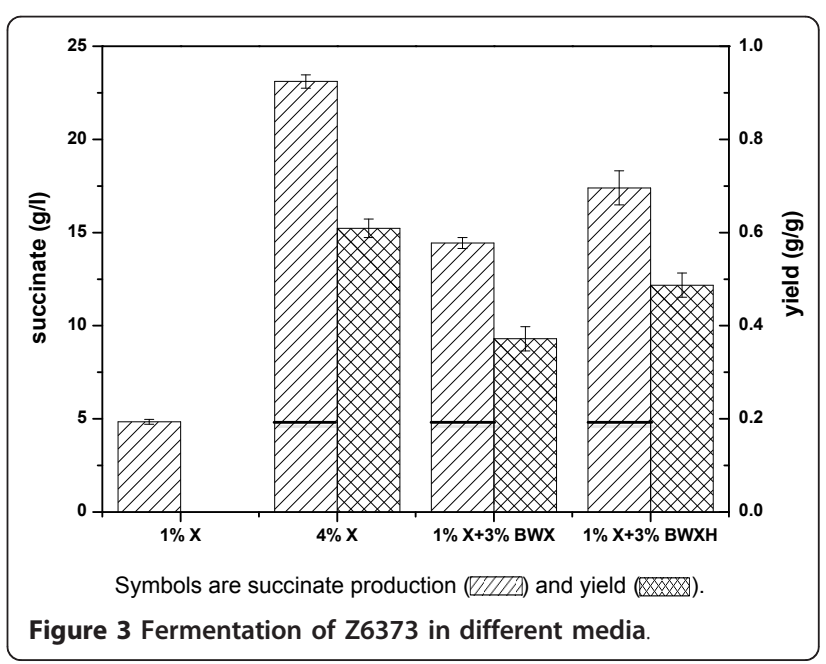


conducted, the actual yield in anaerobic stage was hard to calculate accurately. In the following yield calculations, succinate produced from AM1/1\% xylose $(4.84 \mathrm{~g} /$ l) was subtracted. The differences were used to calculate succinate yields directly from carbon sources, including xylose, xylan and xylan acid hydrolysates.

A batch fermentation of Z6373 resulted in $14.44 \mathrm{~g} / \mathrm{l}$ succinate at $120 \mathrm{~h}$ with $1 \%$ xylose and $3 \%$ xylan as substrates anaerobically, representing a yield of about 0.37 g/g xylan. Considering there were $9 \%$ hydrolyzed reducing sugars cannot be directly used by $E$. coli, the actual succinate yield would be higher. As shown in Figure 3, the yield from pure xylose was about $0.61 \mathrm{~g} / \mathrm{g}$ xylose. The succinate yield from $10 \mathrm{~g} / \mathrm{l}$ xylose was $4.84 \mathrm{~g} / \mathrm{l}$, so the succinate concentration of $14.44 \mathrm{~g} / \mathrm{l}$ was a result of continued hydrolysis and fermentation of xylan during the anaerobic cultivation stage. To assess the extent of hydrolysis by hemicellulases in the fermentation process, acid hydrolysates (BWXH) were prepared and subsequently fermented by the strain. The succinate yield from acid hydrolysates was $0.49 \mathrm{~g} / \mathrm{g}, 31 \%$ higher than that from xylan. The overall yield of succinate from beechwood xylan was lower than anticipated, which was not surprising. This is primarily due to incomplete xylan hydrolysis, as only three types of hemicellulases were produced. The consumption of carbon flux and energy flux for hemicellulases production and secretion was also a reason involved. The anaerobic productivities and yields in this study were somewhat lower than that reported in studies of producing succinate from lignocellulosic biomass [20,21]. However, those studies used complex medium, and the process of succinate production was discrete with the process of the lignocellulose hydrolysis, while in this work a CBP was conducted in minimal medium. We recognize that commercialization will require another two- to four-fold increase of production yield and much less fermentation time. However, the ability to directly use lower-cost crude feedstock will make biological succinate production more economically attractive, and feedstock flexibility will allow manufacturers to take advantage of geographic differences in sugar availability. Anyway, the final yield from xylan in this study was about $76 \%$ of that obtained from acid hydrolysates, indicating that significant hydrolysis was achieved by just co-expression of three hemicellulases.

To enable better expression of the xylanase genes, a microaerobic culture was tested. However, succinate produced under the microaerobic condition was much less than that under strict anaerobic condition (data not shown). This result was not unexpected, considering the traces of oxygen expected to supply for xylanase expression was preferentially diverted into the biomass formation flux, and most of the reducing sugars hydrolyzed by the xylanases were also changed to that channel. In microaerobic and aerobic cultures, a considerable part of carbon flux is used for cell growth which will be significantly affected the product output. This phenomenon is widespread in the conventional microaerobic or aerobic fermentation, which is much more serious for CBP as the monosaccharides supply is the bottleneck. In anaerobic fermentation, the strains were almost ceased to grow. Almost all the hydrolyzed sugars were converted into products. This indicated that anaerobic fermentation was more advantageous than microaerobic and aerobic fermentations with CBP of polysaccharides.

\section{Conclusions}

This report represents a promising step towards the goal of hemicellulosic chemical production. In this work the production of succinate from hemicellulose was performed by $E$. coli strains via consolidated bioprocessing. Fusing with OsmY respectively, hemicellulases were secreted extracellularly with considerable enzyme activities. With three hemicellulases and a pyruvate carboxylase co-expressed, the engineered E. coli Z6373 was able to produce $0.37 \mathrm{~g} / \mathrm{g}$ succinate from xylan anaerobically equivalent to $76 \%$ of that from xylan acid hydrolysates. This is the first example of culture designed and engineered specifically for CBP of xylan to succinate without using externally supplied hydrolases and any other organic nutrient. The ability to use lower-cost crude feedstock will make biological succinate production more economically attractive.

\section{Methods}

\section{Strains, plasmids, and primers}

E. coli strain TOP10 was used for propagation and amplification of plasmids; while $E$. coli strain BL21 (DE3) was employed for enzyme assays and characterizations and E. coli strain W1485 was engineering for succinate production. The features and descriptions of the used strains and plasmids in the present study are listed in Table 5. General recombinant DNA manipulations were performed by standard procedures [40]. All PCRs were carried out under the manufacturer's recommended conditions (Toyobo, Osaka, Japan). The primers used in the PCRs are listed in Table 6.

\section{Operons and plasmids construction}

The osmotically inducible protein Y gene (osm Y [GenBank: CAQ34734]) was amplified from E. coli BL21 (DE3) genomic DNA using primers osmY-f and osmY-r, starting with a strong ribosome-binding sites and ending with a glycine-serine linker.

Three endoxylanase genes and four xylosidase genes (Table 1) were codon-optimized for enhanced expression in $E$. coli, and some restriction sites were added or 
Table 5 Strains and plasmids used in this study

\begin{tabular}{|c|c|c|}
\hline Strain & Genotype & Source \\
\hline E. coli W1485 & $F^{+}$rpoS396(Am)rph-1 & Lab stocked \\
\hline E. coli BL21 (DE3) & $F^{\prime}$ ompT gal dcm lon hsdSB(rB- mB-) $\lambda(D E 3$ [lacl lacUV5-T7 gene 1ind1 sam7 nin5]) & Novagen \\
\hline E. coli TOP10 & F' mcrA $\Delta$ (mrr-hsdRMS-mcrBC) $\Phi 80 l a c Z$ M15 $\Delta a c X 74$ recA1 araD139D(ara-leu) 7697 galU galK rpsL (Strr) endA1 nupG & Invitrogen \\
\hline Z0001 & BL21 (DE3): $\Delta / p p$ & This study \\
\hline Z0003 & W1485: $\Delta / d h A, \Delta p t s G:: c a t, \Delta p f l B:: k a n$ & This study \\
\hline Z1000 & BL21 (DE3): pTrc99z & This study \\
\hline Z1EX0 & BL21 (DE3): pA- $E_{m} X_{n}$ & This study \\
\hline Z1371 & Z0001: $\mathrm{pA}-\mathrm{E}_{3} \mathrm{X}_{7}$ & This study \\
\hline Z2370 & BL21 (DE3): $p A-E_{3} X_{7} D$ & This study \\
\hline $\mathrm{Z3000}$ & BL21 (DE3): pTrc15a & This study \\
\hline Z3370 & BL21 (DE3): $p B-E_{3} X_{7}$ & This study \\
\hline Z3371 & Z0001: $p B-E_{3} X_{7}$ & This study \\
\hline$Z 4370$ & $B L 21$ (DE3): $p B-E_{3} X_{7} D$ & This study \\
\hline Z5370 & BL21 (DE3): $p B-E_{3} X_{7} A D$ & This study \\
\hline Z6373 & Z0003: $p B-E_{3} X_{7} A Y D$ & This study \\
\hline Plasmid & Description & Source \\
\hline pUC57-Em & pMB1 ori, $P_{\text {lac }}$ : endoxylanase gene $\left(E_{1}, E_{2}\right.$ or $E_{3}$ gene), Amp ${ }^{r}$ & Genscript \\
\hline $\mathrm{pUC57-X_{n }}$ & pMB1 ori, $P_{\text {lac: }}$ xylosidase gene $\left(X_{4}, X_{5}, X_{6}\right.$ or $X_{7}$ gene), Amp ${ }^{r}$ & Genscript \\
\hline pUC57- $E_{m} X_{n}$ series & 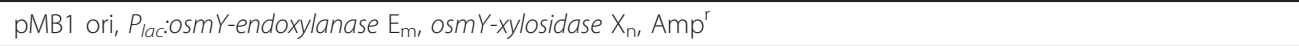 & This study \\
\hline pTrc99a & pBR322 ori, Ampr & Invitrogen \\
\hline pTrc99z & pBR322 ori, $A m p^{r}$ & This study \\
\hline$p A-E_{m} X_{n}$ series & 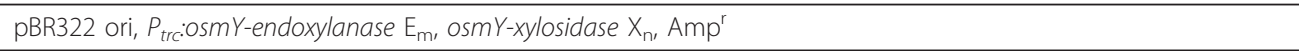 & This study \\
\hline$p A-E_{3} X_{7} D$ & pBR322 ori, $P_{\text {trc: }}$ osmY-xynC-A, osmY-xyloA; PdsbA: dsbA, Amp ${ }^{r}$ & This study \\
\hline pACYC184 & p15a ori, Cat ${ }^{r}$ Tet $^{r}$ & NEB \\
\hline$\overline{p \operatorname{Trc15a}}$ & p15a ori, Ampr & This study \\
\hline$p B-E_{3} X_{7}$ & p15a ori, $P_{\text {trc: }}$ osmY-xynC-A, osmY-xyloA, Amp ${ }^{r}$ & This study \\
\hline $\mathrm{pB}-\mathrm{E}_{3} \mathrm{X}_{7} \mathrm{D}$ & p15a ori, $P_{\text {trc: }}$ osmY-xynC-A, osmY-xyloA; PdsbA: dsbA, Ampr & This study \\
\hline $\mathrm{pB}-\mathrm{E}_{3} \mathrm{X}_{7} \mathrm{OD}$ & p15a ori, $P_{\text {trc: }}$ osmY-xynC-A, osmY-xyloA, osmY; PdsbA: dsbA, Amp ${ }^{r}$ & This study \\
\hline $\mathrm{pB}-\mathrm{E}_{3} \mathrm{X}_{7} \mathrm{AD}$ & p15a ori, $P_{\text {trc: }}$ osmY-xynC-A, osmY-xyloA, osmY-abf2; PdsbA: dsbA, Ampr & This study \\
\hline$\overline{p B-E_{3} X_{7} A Y D}$ & p15a ori, $P_{\text {trc }}:$ osmY-xynC-A, osmY-xyloA, osmY-abf2; $P_{t r c}: p y c ; P d s b A: d s b A, A m p^{r}$ & This study \\
\hline
\end{tabular}

Table 6 Primers used in this study

\begin{tabular}{|c|c|}
\hline Primer name & DNA sequence $\left(5^{\prime}-3^{\prime}\right)$ \\
\hline osmY-f & GCGGAATTCATGAGATCTGGCTAACATAGGGTGGATCTATGACTATGACAAGACTGAAG \\
\hline osmY-r & AATCTCGAGTTAGGATCCCCCGCTACCACTGCCCGAACCCTTAGTTITCAGATCATTTT \\
\hline 99zD-f & ACATACCTCGAGCGCCTTTGAGTGAGCTGATA \\
\hline $99 z D-r$ & CGACACTAGTTGATCTITTCTACGGGGTC \\
\hline trc-f & GCAGCAATTGCGCGTATACGACAGCTTATCATCGACTG \\
\hline trc-r & GTCGACTCTAGAGGATCC \\
\hline dsb-f & GTACGAGCATATGTTCGACACCGCTGAAATCGG \\
\hline dsb-r & AGCGCAGCATATGACGGCTAACGCAACAATAACACCT \\
\hline $184-f$ & GCATACTAGTGGCTTCCCGGTATCAACA \\
\hline $184-r$ & CTATCTCGAGCAGTACCGGCATAACCAAGC \\
\hline abf2-f & GCCAGGATCCATGTCTGAACATCAAGCA \\
\hline$a b f 2-r$ & GCCATCTAGAGCATGACGTCTTAAGAATCAGCACGCAG \\
\hline pyc-f & GCTGGAGCTCGACGCAATTGGGCTAACATAGGGTGGATCTATGTCGACTCACACATCTT \\
\hline pyc-r & CTGCTCTAGATTAGGAAACGACGACGATC \\
\hline
\end{tabular}


eliminated to simplify subsequent manipulations according to the Bglbrick standard [41]. The seven codon-optimized genes were synthesized in the form of Bglbricks, and subsequently inserted into a modified pUC57 Bglbrick vector, respectively, resulting in three pUC57$\mathrm{E}_{\mathrm{m}}(\mathrm{m}=1,2$ or 3$)$ and four pUC57-X $\mathrm{n}(\mathrm{n}=4,5,6$ or 7) plasmids (Genscript, Nanjing, China). According to the Bglbrick standard assembly, osm $Y$ was fused with different xylanase genes via the glycine-serine linker by inserting it into the seven pUC57- $E_{m}$ and pUC57- $X_{n}$ plasmids, respectively. The four resulting OsmY-xylosidase fusion genes were then recut and assembled with the other three plasmids containing OsmY-endoxylanase fusion gene to obtain twelve OsmY-endoxylanaseOsmY-xylosidase $\left(E_{m} X_{n}\right)$ gene combinations presented in pUC57- $\mathrm{E}_{\mathrm{m}} \mathrm{X}_{\mathrm{n}}$ plasmids, respectively.

A slightly modified medium-copy plasmid for the Bglbrick insertions, pTrc99z, was constructed by removing $14 \mathrm{bp}$ ribosome-binding sites fragment downstream the trc promoter from pTrc99a. Twelve $\mathrm{pA}-\mathrm{E}_{\mathrm{m}} \mathrm{X}_{\mathrm{n}}$ plasmids were constructed by cloning the corresponding EcoRI-BamHI digested $\mathrm{E}_{\mathrm{m}} \mathrm{X}_{\mathrm{n}}$ gene fragment from $\mathrm{pUC} 57-\mathrm{E}_{\mathrm{m}} \mathrm{X}_{\mathrm{n}}$ on $\mathrm{p} \operatorname{Trc} 99 \mathrm{z}$ for in vitro characterizations of xylanases.

The disulfide isomerase I gene ( $d s b A$ [GenBank: ACT45539]) was amplified from E. coli BL21 (DE3) genomic DNA using primers Dsb-f and Dsb-r, digested with $N d e I$, and ligated into the same restriction site of $\mathrm{pA}-\mathrm{E}_{3} \mathrm{X}_{7}$, resulting in $\mathrm{pA}-\mathrm{E}_{3} \mathrm{X}_{7} \mathrm{D}$.

Plasmids pTrc15a, pB- $E_{3} X_{7}$ and $p B-E_{3} X_{7} D$ were constructed form $\mathrm{pTrc} 99 \mathrm{z}, \mathrm{pA}-\mathrm{E}_{3} \mathrm{X}_{7}$ and $\mathrm{pA}-\mathrm{E}_{3} \mathrm{X}_{7} \mathrm{D}$ respectively by replacing the $\mathrm{pBR} 322$ origin with $\mathrm{p} 15 \mathrm{a}$ origin of pACYC184 using primers 99ZD-f, 99ZD-r, 184-f and 184-r.

The osm $Y$ gene digested with $B g l \mathrm{II}-\mathrm{BamHI}$ was ligated to the $\mathrm{BamHI}$ restriction sites of $\mathrm{pB}-\mathrm{E}_{3} \mathrm{X}_{7} \mathrm{D}$, resulting in $\mathrm{pB}-\mathrm{E}_{3} \mathrm{X}_{7} \mathrm{OD}$. The $a b f 2$ gene [GenBank: EU073712] which encodes an $\alpha$-arabinofuranosidase amplified from Bacillus subtilis 168 genomic DNA using primers abf2-f and abf2-r was cloned into the BamHI-SalI sites of pB$\mathrm{E}_{3} \mathrm{X}_{7} \mathrm{OD}$ to generate plasmid $\mathrm{pB}-\mathrm{E}_{3} \mathrm{X}_{7} \mathrm{AD}$.

A $300 \mathrm{bp}$ fragment containing $\operatorname{trc}$ promoter was amplified from $\mathrm{p} \operatorname{Trc} 99 \mathrm{z}$ using primers trc- $\mathrm{f}$ and trc-r, digested with $M f e I$ and $X b a I$, and subsequently ligated into the EcoRI-XbaI sites of pUC18 to generate plasmid pUC18T. The pyruvate carboxylase gene (pyc [GenBank: CAA70739]) was amplified from Corynebacterium glutamicum ATCC 13032 chromosome using primers pyc-f and pyc-r with the GTG start codon changing to ATG, and inserted into the SacI-XbaI sites of pUC18T to generate plasmid pUC18TY. Then the fragment containing trc promoter and pyc was cut with $A f e \mathrm{I}$ and SpeI from pUC18TY, and cloned into $\mathrm{pB}-\mathrm{E}_{3} \mathrm{X}_{7} \mathrm{AD}$ at the BstZ171$\mathrm{XbaI}$ sites to yield plasmid $\mathrm{pB}-\mathrm{E}_{3} \mathrm{X}_{7} \mathrm{AYD}$.

\section{Gene inactivation}

The method used for the deletion of genes in the chromosome of E. coli including lpp, ldhA, pflB and $p t s G$ was based on the utilization of $\lambda$ Red-mediated recombination [42]. If necessary, the FRT-flanked resistance cassette was removed from genome with the helper plasmid pCP20.

\section{Media and cultivation conditions}

Engineering strains were cultured in LB, M9 [43], NBS or AM1 [44] medium as indicated. Appropriate antibiotics were added for plasmid maintenance or gene deletion (ampicillin at $100 \mu \mathrm{g} / \mathrm{ml}$, kanamycin at $20 \mu \mathrm{g} / \mathrm{ml}$ or chloramphenicol at $5 \mu \mathrm{g} / \mathrm{ml}$ ).

Xylanases characterization was operated in a $100 \mathrm{ml}$ shake-flask cultivation using M9/1\% glucose minimal medium. Protein expression was induced with $0.5 \mathrm{mM}$ IPTG when the $\mathrm{OD}_{600}$ reached about 0.7. Simultaneously the growth temperature was switched from $37^{\circ}$ $\mathrm{C}$ to $30^{\circ} \mathrm{C}$ with the agitation rate set at $200 \mathrm{rpm}$. Cells were incubated for an additional $16 \mathrm{~h}$. Samples were taken periodically to monitor cell growth $\left(\mathrm{OD}_{600}\right)$, protein, and reducing sugar concentration.

Xylan (xylose)-to-succinate conversion was detected in NBS and AM1 minimal medium. Cells were aerobically grown in a $250 \mathrm{ml}$ Erlenmeyer flask containing $50 \mathrm{ml}$ NBS/1\% xylose medium with the temperature maintained at $37^{\circ} \mathrm{C}$. When the $\mathrm{OD}_{600}$ reached 2.5 , cells were harvested by centrifugation at $4000 \mathrm{~g}$. Washed once with distilled water, the cells were suspended in a $250 \mathrm{ml}$ Erlenmeyer flask containing $20 \mathrm{ml}$ AM1 medium supplemented with $4 \%$ carbon source as described yielding an initial $\mathrm{OD}_{600}$ of approximately 6. Simultaneously, the cultures were induced with $0.5 \mathrm{mM}$ IPTG. Two hours after induction, anaerobic cultivation was started by transferring the cultures into a $100 \mathrm{ml}$ bottle sealed with a sterile stopper, while $\mathrm{NaHCO}_{3}$ and $\mathrm{MgCO}_{3}$ (basic) were added to a final concentration of $0.1 \mathrm{M}$ each. Microaerobic conditions were also used for succinate production, which were established by piercing the stopper with a $16 \mathrm{G}$ needle (Becton-Dickenson, San Jose, USA) after inoculation. The needle was kept in the bottle during growth to allow a small amount of air to enter. Cells were incubated anaerobically or microaerobically for an additional $120 \mathrm{~h}$ at $30^{\circ} \mathrm{C}$ with the agitation rate set at $200 \mathrm{rpm}$ unless otherwise indicated in the text.

Acid hydrolysates of beechwood xylan were prepared as described [45]. The same fermentation conditions described above were used, except that the carbon source in AM1 medium was 1\% xylose plus 3\% (wt/vol) acid hydrolysates.

\section{Protein and enzyme analysis}

Endoxylanase activities were determined using beechwood xylan as substrate in cell-free media by a modified 
method described [46]. The reducing sugar liberated in the reaction mixture was measured by the DNS method [47], and D-xylose was used as the standard. Xylosidase activities were measured using $\mathrm{p}$-nitrophenyl- $\beta$-xylose (Sigma-Aldrich, St. Louis, USA) as substrate [24]. Those reactions were performed at $30^{\circ} \mathrm{C}$ for $40 \mathrm{~min}$. One unit of enzyme activity was defined as the amount of enzyme that released $1 \mu \mathrm{mol}$ of product (xylose or p-nitrophenol) equivalents in 1 min under the assay conditions.

Extracellular and intracellular protein fractions were prepared according to the method described in the pET system manual (EMD Chemicals, San Diego, USA). Protein concentration of each fractionated sample was determined as described by Bradford [48] with the commercial Bradford reagent (Sigma-Aldrich). SDS-PAGE was performed using $4 \%$ acrylamide stacking gel and $12 \%$ acrylamide resolving gel as described by Laemmli [49]. Protein bands were detected using Coomassie blue staining.

\section{Fermentation process analysis}

Cell growth was monitored by measuring the optical density at $600 \mathrm{~nm}\left(\mathrm{OD}_{600}\right)$ with a UV-vis spectrophotometer (TU-1901, Persee, Beijing, China).

Fermentation products were analyzed by HPLC (HP1100, Agilent Technologies, Palo Alto, USA), using an ion exclusion Aminex HPX 87-H column (Bio-Rad, Richmond, USA) with $5 \mathrm{mM} \mathrm{H}_{2} \mathrm{SO}_{4}$ as the mobile phase at $0.6 \mathrm{ml} / \mathrm{min}$ flow rate, $55^{\circ} \mathrm{C}$ column temperature and UV absorption at $210 \mathrm{~nm}$ [19]. All samples for HPLC analysis were centrifuged at $13000 \mathrm{~g}$ for $10 \mathrm{~min}$, and filtered through $0.2 \mu \mathrm{m}$ filters before analysis.

\section{Acknowledgements \\ This work was supported by National 973 Project (2011CBA00804 2012CB725203), National Natural Science Foundation of China (NSFC- 21176182) and the project of introducing talents of discipline to universities (B06006)}

\section{Author details \\ ${ }^{1}$ Key Laboratory of Systems Bioengineering, Ministry of Education, Tianjin University, Tianjin 300072, People's Republic of China. ${ }^{2}$ Department of Biochemical Engineering, School of Chemical Engineering and Technology, Tianjin University, Tianjin 300072, People's Republic of China.}

\section{Authors' contributions}

$\mathrm{ZZ}$ and $\mathrm{MZ}$ performed the experiments under the guidance of $\mathrm{TC} . \mathrm{ZZ}$ analyzed the experimental data and drafted the manuscript. TC and ZW made substantial contributions to conception, interpretation of data and revised the manuscript. TC, XZ and ZZ developed the idea for the study and designed the research. All authors read and approved the final manuscript.

\section{Competing interests}

The authors declare that they have no competing interests.

Received: 7 February 2012 Accepted: 29 March 2012 Published: 29 March 2012
References

1. Burchhardt $\mathrm{G}$, Ingram LO: Conversion of xylan to ethanol by ethanologenic strains of Escherichia coli and Klebsiella oxytoca. Appl Environ Microbiol 1992, 58(4):1128-1133.

2. Saha BC: Hemicellulose bioconversion. J Ind Microbiol Biot 2003, 30(5):279-291

3. Timell TE: Wood Hemicelluloses: Part I Advances in Carbohydrate Chemistry.Edited by: Melville LW. New York: Academic; 19 1964:247-302.

4. Steen EJ, Kang YS, Bokinsky G, Hu ZH, Schirmer A, McClure A, de Cardayre SB, Keasling JD: Microbial production of fatty-acid-derived fuels and chemicals from plant biomass. Nature 2010, 463(7280):559-562.

5. Latif F, Rajoka Ml: Production of ethanol and xylitol from corn cobs by yeasts. Bioresource Technol 2001, 77(1):57-63.

6. Willquist K, Zeidan AA, van Niel EW: Physiological characteristics of the extreme thermophile Caldicellulosiruptor saccharolyticus: an efficient hydrogen cell factory. Microb Cell Fact 2010, 9:89.

7. Lee H, Biely P, Latta RK, Barbosa MF, Schneider H: Utilization of Xylan by Yeasts and Its Conversion to Ethanol by Pichia stipitis Strains. App/ Environ Microbiol 1986, 52(2):320-324.

8. Menon V, Prakash G, Prabhune A, Rao M: Biocatalytic approach for the utilization of hemicellulose for ethanol production from agricultural residue using thermostable xylanase and thermotolerant yeast. Bioresource Technol 2010, 101(14):5366-5373.

9. Lynd LR, Weimer PJ, van ZyI WH, Pretorius IS: Microbial cellulose utilization: Fundamentals and biotechnology. Microbiol Mol Biol R 2002, 66(3):506-577

10. Wyman CE: Potential synergies and challenges in refining cellulosic biomass to fuels, chemicals, and power. Biotechnol Progr 2003, 19(2):254-262.

11. Palmqvist $E$, Hahn-Hagerdal B: Fermentation of lignocellulosic hydrolysates. II: inhibitors and mechanisms of inhibition. Bioresource Technol 2000, 74(1):25-33.

12. Lynd LR, van Zyl WH, McBride JE, Laser M: Consolidated bioprocessing of cellulosic biomass: an update. Curr Opin Biotech 2005, 16(5):577-583.

13. Pugsley AP, Francetic O: Protein secretion in Escherichia coli K-12: dead or alive? Cell Mol Life Sci 1998, 54(4):347-352.

14. Qian ZG, Xia XX, Choi JH, Lee SY: Proteome-based identification of fusion partner for high-level extracellular production of recombinant proteins in Escherichia coli. Biotechnol Bioeng 2008, 101(3):587-601.

15. French CE: Synthetic biology and biomass conversion: a match made in heaven? Journal of the Royal Society Interface 2009, 6(Suppl 4):389-391.

16. Werpy T, Frye J, Holladay J: Succinic Acid - A Model Building Block for Chemical Production from Renewable Resources. In Biorefineries-Industrial Processes and Products. Edited by: Kamm B, Gruber PR, Kamm M. Weinheim: Wiley-VCH Verlag GmbH; 2008:367-379.

17. Zeikus JG, Jain MK, Elankovan P: Biotechnology of succinic acid production and markets for derived industrial products. Appl Microbiol Biot 1999, 51(5):545-552.

18. Lee KY, Park JM, Kim TY, Yun H, Lee SY: The genome-scale metabolic network analysis of Zymomonas mobilis ZM4 explains physiological features and suggests ethanol and succinic acid production strategies. Microb Cell Fact 2010, 9:94.

19. Andersson C, Hodge D, Berglund KA, Rova U: Effect of different carbon sources on the production of succinic acid using metabolically engineered Escherichia coli. Biotechnol Progr 2007, 23(2):381-388.

20. Donnelly MI, Sanville-Millard CY, Nghiem NP: Method to produce succinic acid from raw hydrolysates. US Patent 2004, 6743610.

21. Hodge DB, Andersson C, Berglund KA, Rova U: Detoxification requirements for bioconversion of softwood dilute acid hydrolyzates to succinic acid. Enzyme Microb Tech 2009, 44(5):309-316.

22. Wang D, Li QA, Yang MH, Zhang YJ, Su ZG, Xing JM: Efficient production of succinic acid from corn stalk hydrolysates by a recombinant Escherichia coli with ptsG mutation. Process Biochem 2011, 46(1):365-371.

23. Lafond M, Tauzin A, Desseaux V, Bonnin E, Ajandouz EH, Giardina T: GH10 xylanase D from Penicillium funiculosum: biochemical studies and xylooligosaccharide production. Microb Cell Fact 2011, 10:20.

24. Carapito R, Carapito C, Jeltsch JM, Phalip V: Efficient hydrolysis of hemicellulose by a Fusarium graminearum xylanase blend produced at high levels in Escherichia coli. Bioresource Technol 2009, 100(2):845-850. 
25. Adelsberger H, Hertel C, Glawischnig E, Zverlov W, Schwarz WH: Enzyme system of Clostridium stercorarium for hydrolysis of arabinoxylan: reconstitution of the in vivo system from recombinant enzymes. Microbiol-sgm 2004, 150:2257-2266.

26. Marrone $L$, McAllister KA, Clarke AJ: Characterization of function and activity of domains A, B and C of xylanase C from Fibrobacter succinogenes S85. Protein Eng 2000, 13(8):593-601.

27. Whitehead TR, Hespell RB: The genes for three xylan-degrading activities from Bacteroides ovatus are clustered in a 3.8-kilobase region. J Bacteriol 1990, 172(5):2408-2412.

28. Xu WZ, Shima Y, Negoro S, Urabe I: Sequence and properties of betaxylosidase from Bacillus pumilus IPO. Contradiction of the previous nucleotide sequence. Eur J Biochem 1991, 202(3):1197-1203.

29. Whitehead TR, Cotta MA: Identification of a broad-specificity xylosidase/ arabinosidase important for xylooligosaccharide fermentation by the ruminal anaerobe Selenomonas ruminantium GA192. Curr Microbiol 2001, 43(4):293-298.

30. Dekker RF: Bioconversion of hemicellulose: aspects of hemicellulase production by Trichoderma reesei QM 9414 and enzymic saccharification of hemicellulose. Biotechnol Bioeng 1983, 25(4):1127-1146.

31. Ni Y, Reye J, Chen RR: Ipp deletion as a permeabilization method. Biotechnol Bioeng 2007, 97(6):1347-1356.

32. Shin HD, Chen RR: Extracellular Recombinant Protein Production From an Escherichia coli Ipp Deletion Mutant. Biotechnol Bioeng 2008, 101(6):1288-1296.

33. Jeong KJ, Lee SY: Secretory production of human leptin in Escherichia coli. Biotechnol Bioeng 2000, 67(4):398-407.

34. Goff SA, Goldberg AL: Production of abnormal proteins in E. coli stimulates transcription of lon and other heat shock genes. Cell 1985, 41(2):587-595.

35. Thakker C, Zhu JF, San KY, Bennett G: Heterologous pyc gene expression under various natural and engineered promoters in Escherichia coli for improved succinate production. J Biotechnol 2011, 155(2):236-243.

36. Chang AC, Cohen SN: Construction and characterization of amplifiable multicopy DNA cloning vehicles derived from the P15A cryptic miniplasmid. J Bacteriol 1978, 134(3):1141-1156.

37. Kormelink FJM, Voragen AGJ: Degradation of different [(glucurono) arabino]xylans by a combination of purified xylan-degrading enzymes. Appl Microbiol Biot 1993, 38(5):688-695.

38. Inacio JM, Correia IL, de Sa-Nogueiral I: Two distinct arabinofuranosidases contribute to arabino-oligosaccharide degradation in Bacillus subtilis. Microbiol-sgm 2008, 154:2719-2729.

39. Yao R, Hirose Y, Sarkar D, Nakahigashi K, Ye Q, Shimizu K: Catabolic regulation analysis of Escherichia coli and its $c r p, m / c, m g s A$, pgi and ptsG mutants. Microb Cell Fact 2011, 10:67.

40. Sambrook J: Russell DW: Molecular cloning: a laboratory manual. New York: CSHL press; 20012.

41. Anderson JC, Dueber JE, Leguia M, Wu GC, Goler JA, Arkin AP, Keasling JD: BglBricks: A flexible standard for biological part assembly. J Biol Eng 2010, 4(1):1

42. Wanner BL, Datsenko KA: One-step inactivation of chromosomal genes in Escherichia coli K-12 using PCR products. P Natl Acad Sci Usa 2000, 97(12):6640-6645.

43. Tsuruta H, Paddon CJ, Eng D, Lenihan JR, Horning T, Anthony LC, Regentin R, Keasling JD, Renninger NS, Newman JD: High-level production of amorpha-4,11-diene, a precursor of the antimalarial agent artemisinin, in Escherichia coli. PLoS One 2009, 4(2):e4489.

44. Martinez A, Grabar TB, Shanmugam KT, Yomano LP, York SW, Ingram LO: Low salt medium for lactate and ethanol production by recombinant Escherichia coli B. Biotechnol Lett 2007, 29(3):397-404.

45. Pazur JH: Neutral polysaccharides. In Carbohydrate analysis: a practical approach. Edited by: Chaplin MF, Kennedy JF. Washington: IRL Press; 1986:55-96.

46. Biely P, Mislovicova D, Toman R: Soluble chromogenic substrates for the assay of endo-1,4-beta-xylanases and endo-1,4-beta-glucanases. Anal Biochem 1985, 144(1):142-146.

47. Chaplin MF: Monosaccharides. In Carbohydrate analysis: a practical approach. Edited by: Chaplin MF, Kennedy JF. Washington: IRL Press; 1986:1-36
48. Bradford MM: A rapid and sensitive method for the quantitation of microgram quantities of protein utilizing the principle of protein-dye binding. Anal Biochem 1976, 72(1):248-254.

49. Laemmli UK: Cleavage of structural proteins during the assembly of the head of bacteriophage T4. Nature 1970, 227(5259):680-685.

\section{doi:10.1186/1475-2859-11-37}

Cite this article as: Zheng et al:: Engineering Escherichia coli for succinate production from hemicellulose via consolidated bioprocessing. Microbial Cell Factories 2012 11:37.

\section{Submit your next manuscript to BioMed Central and take full advantage of:}

- Convenient online submission

- Thorough peer review

- No space constraints or color figure charges

- Immediate publication on acceptance

- Inclusion in PubMed, CAS, Scopus and Google Scholar

- Research which is freely available for redistribution

Submit your manuscript at www.biomedcentral.com/submit
Biomed Central 